\title{
Acquired angioedema
}

INSERM

\section{Source}

INSERM. (1999). Orphanet: an online rare disease and orphan drug data base. Acquired angioedema. ORPHA:91385

Acquired angioedema (AAE) is characterized by the occurrence of transitory and recurrent subcutaneous and/or submucosal edemas resulting in swelling and/or abdominal pain due to an acquired $\mathrm{C} 1$ inhibitor (C1-INH) deficiency. 